\title{
The radiation safety of the designing constructions in radon-hazardous areas
}

\author{
Igor Shubin ${ }^{1}$, Natalya Bakaeva $^{2}$,Alexander Kalaydo ${ }^{3, *}$, Anna Skrynnykova ${ }^{3}$ \\ ${ }^{1}$ Russian Academy of Architecture and Building Science Research Institute of Building Physics, \\ 127238, Moscow, Russia \\ ${ }^{2}$ Southwest State University, 305040, Kursk, Russia \\ ${ }^{3}$ Lugansk Taras Shevchenko National University, 91011, Lugansk
}

\begin{abstract}
The radiation safety of the designing constructions is quite a challenge problem due to the multifactorial nature of the process of forming an internal radon situation. The particular importance is the successful solution of potentially radon-hazardous areas, where the acceptable levels of radon in the indoor air cannot be provided without implementing a set of special radon-protective measures. The article defines the dominant mechanism of radon transportation in soils and walling materials on the basis of their permeability. The recommendations for designing underground walling structures with the required radonprotective characteristics have been proposed. It is shown that radon safety of buildings can be provided on soils with a high natural radionuclides content using exclusively passive radon protection technologies.
\end{abstract}

\section{Introduction}

Radon in the indoor air has long been recognized as the main factor in the formation of the radiation capacity on the population. Understanding the importance of the radon problem has led to the consolidation of radon control levels, the excess these levels is unacceptable in buildings with long residence of people. In the Russian Federation the equivalent equilibrium radon concentration (EERC) in the indoor air should not exceed $100 \mathrm{~Bq} \cdot \mathrm{m}^{-3}$. This corresponds to the range from 200 to $250 \mathrm{~Bq} \cdot \mathrm{m}^{-3}$ value of radon concentration used as a radon hazard criterion in Europe and North America.

Most radon enters into the premises from the soil [1-3] and its entry intensity is determined by the geophysical soil characteristics, but it can be widely controlled by the technologies and materials used in the construction of the underground building shell [4]. The radiation security of the constructions being erected is an urgent scientific and practical problem. Its effective solution is possible only at the design stage, since measures aimed at the normalization of the radon situation in the facilities in operation require significantly higher costs.

\footnotetext{
*Corresponding author: kalaydo18@mail.ru
} 
The most important rational design of underground walling is for radon-hazard territories formed by soils with a high content of natural radionuclides. Radon safety of buildings on these territories cannot be provided solely by sealing the underground building shell, therefore it is necessary to include in the floor construction additional layers with high radon resistance or use of active protection technologies aimed at removing radon entering the room. In such conditions a reliable method is needed for calculating the required radonprotective characteristics of underground walling, which based on the geophysical characteristics of the soil at the planned construction site.

There are a number of potential radon danger signs of a territory [5; 6], which in a certain values combination are capable to forming high radon levels in buildings even in radon-safe flatlands. However, two of them play a decisive role in determining the degree of territories radon danger - there are the radium content in soil and soil permeability.

In the Russian Federation the radon danger of the Altai and North Caucasus territories is well known which due to the release of uranium-bearing ores to the surface [7]. Abroad, the territories of the Scandinavian countries formed by uranium-rich granites and alum schists, as well as highly permeable glacial deposits, are considered the most radon-dangerous [8].

\section{Results and discussions}

Radon is formed in the soil under the building from the parent radium and with the soil air is transferred to the building underground walling. Its typical concentration in the soil air up to $50 \mathrm{kBq} \cdot \mathrm{m}^{-3}$, the higher concentration values indicate the radon danger of the territory [8]. There are cases when the radon concentrations in the soil air reached $1-2 \mathrm{MBq} \cdot \mathrm{m}^{-3}[8 ; 9]$, however, they are rare and uncharacteristic even for radon-hazard territories. Radon concentration in the soil can be estimated by the formula

$$
A \approx C_{R a} \cdot \rho_{s} \cdot k
$$

where $C_{R a}$ is the radium specific activity, $\mathrm{Bq} \cdot \mathrm{kg}^{-1} ; \rho_{s}$ is the soil density, $\mathrm{kg} \cdot \mathrm{m}^{-3} ; k$ is the radon emitting coefficient.

Radium concentration in uranium-rich soils can reach $500 \mathrm{~Bq} \cdot \mathrm{m}^{-3}$, therefore with typical soil density values from 1600 to $1900 \mathrm{~kg} \cdot \mathrm{m}^{-3}$ and radon emanation coefficient from 0.3 to 0.6 the radon concentration in soil air will be in the range from 100 to $500 \mathrm{kBq} \cdot \mathrm{m}^{-3}$. The radon decay in soils is compensated by its formation from radium, therefore the radon source power and can be considered constant.

The formed radon transport to the horizontal underground walling is carried out by diffusion and convection and the ratio of these mechanisms contributions is determined by the soil permeability. The typically condition of the soil at under the building and around it is characterized by permeabilities range from $10^{-10}$ to $10^{-13} \mathrm{~m}^{2}$. For this range it makes sense to evaluate the significance of diffusive and convective effects.

The convective radon flow is caused by the pressure gradient in the soil mass which lying in the range from 0.1 to $2 \mathrm{~Pa} \cdot \mathrm{m}^{-1}[10 ; 11]$. Its density is determined by the Darcy law

$$
q_{\text {con }}=\frac{k}{\mu} \cdot \frac{\partial P}{\partial z} \cdot A,
$$

where $k$ is a soil permeability, $\mathrm{m}^{2} ; \mu=1,8 \cdot 10^{-5} \mathrm{~Pa} \cdot \mathrm{s}$ is the dynamic viscosity of soil ideal gas; $\partial P / \partial \mathrm{z}$ is a pressure gradient in soil mass, $\mathrm{Pa} \cdot \mathrm{m}^{-1}$. 
Diffusive transport does not depend on the soil permeability and caused by the radon concentrations difference at the outer borders of the soil block. The radon concentration in indoor air and walling materials is negligible compared to the concentration in the soil air and can be taken as zero. The radon diffusion flux density can be found from the Ficks' law

$$
q_{\text {dif }}=D \cdot \frac{\partial A}{\partial z}
$$

where $D$ is the radon diffusion coefficient in the soil, $\mathrm{m}^{2} \cdot \mathrm{s}^{-1}$.

A change the radon concentration value from almost zero to the maximum size on the soil layer with the thickness rarely exceeds $5 \mathrm{~m}$. In the chart 1 presents a comparative analysis of the diffusion and convective radon fluxes contributions for typical soil permeabilities at the sub-slab zone. The coefficient of radon diffusion in the soil was taken to be equal to $2 \cdot 10^{-7} \mathrm{~m} \cdot \mathrm{s}^{-2}$, the pressure gradient was taken $2 \mathrm{~Pa} \cdot \mathrm{m}^{-1}$ and the radon concentration in the soil air was taken $200 \mathrm{kBq} \cdot \mathrm{m}^{-3}$ in the calculations.

Table 1. The radon flow in the soil structure

\begin{tabular}{|c|c|c|c|c|}
\hline $\boldsymbol{k}, \mathbf{m}^{\mathbf{2}}$ & $\mathbf{1 0}^{-10}$ & $\mathbf{1 0}^{-11}$ & $\mathbf{1 0}^{-12}$ & $\mathbf{1 0}^{-\mathbf{1 3}}$ \\
\hline$q_{\text {con }}, \mathrm{mBq} /\left(\mathrm{m}^{2} \cdot \mathrm{s}\right)$ & 2.22 & 0.22 & 0.02 & $\approx 0$ \\
\hline$q_{d i f}, \mathrm{mBq} /\left(\mathrm{m}^{2} \cdot \mathrm{s}\right)$ & \multicolumn{5}{|c|}{8.0} \\
\hline$q_{\text {tot }}, \mathrm{mBq} /\left(\mathrm{m}^{2} \cdot \mathrm{s}\right)$ & 10.22 & 8.22 & 8.02 & 8.0 \\
\hline
\end{tabular}

The table 1 shows the contribution of convective radon transport in soils should be considered only when their permeabilities are $10^{-11} \mathrm{~m}^{2}$ and higher. The permeability of underground walling materials does not exceed $10^{-12} \mathrm{~m}^{2}[1 ; 12]$ and therefore it is not necessary to take into account the convective radon transport in walling materials.

According to modern trends in construction the radon safety of a building should be provided by underground walling performing the carrier functions. Such radon-protective technologies are called passive. In contrast, active radon-shielding technologies are based on the use of special devices for organizing air exchange or creating excessive pressure in the rooms of the lower floor.

The EERC value in the lower floor room is related to the radon flux density from the soil through the adjacent floor construction by the ratio

$$
E E R C=q_{d i f} \cdot S \cdot F /(V \cdot \lambda),
$$

where $S$ is the floor area, $\mathrm{m}^{2} ; \lambda=2,1 \cdot 10^{-6} \mathrm{~s}^{-1}$ is radon decay constant; $F=0,4 \ldots 0,5$ is the equilibrium factor; $V$ is the room volume, $\mathrm{m}^{3}$.

Again, the density of radon diffusion flux $q_{d i f}$ is determined by the radon load on the building basement and the radon resistance of the floor structure $R$

$$
q_{\text {dif }}=A / R=C_{R a} \cdot \rho_{s} \cdot k / R
$$

The simplest floor construction is a reinforced concrete slab at the building base, its radon resistance is

$$
R=\sqrt{\lambda \cdot D} \cdot \operatorname{sh}(H \cdot \sqrt{\lambda / D})
$$


where $H$ is the base slab thickness, $\mathrm{m} ; D$ - Radon diffusion coefficient in slab material, $\mathrm{m}^{2} \cdot \mathrm{s}^{-1}$.

Substituting (5) and (6) into (4) gives the relationship of radon levels in a building with the soil characteristics and the floor construction features the in the form

$$
E E R C=A \cdot S \cdot F \cdot \sqrt{\lambda \cdot D} /(V \cdot \lambda \cdot \operatorname{sh}(H \cdot \sqrt{\lambda / D}))
$$

In Fig. 1 shows the dependence of EERC in the lower floor room on the base slab thickness $H$ and the radon concentration $A$ in the soil air. The ratio of the room volume to the floor area was taken to be $V / S=3$ and the radon diffusion coefficient in reinforced concrete depended on the base slab thickness (Table 1).

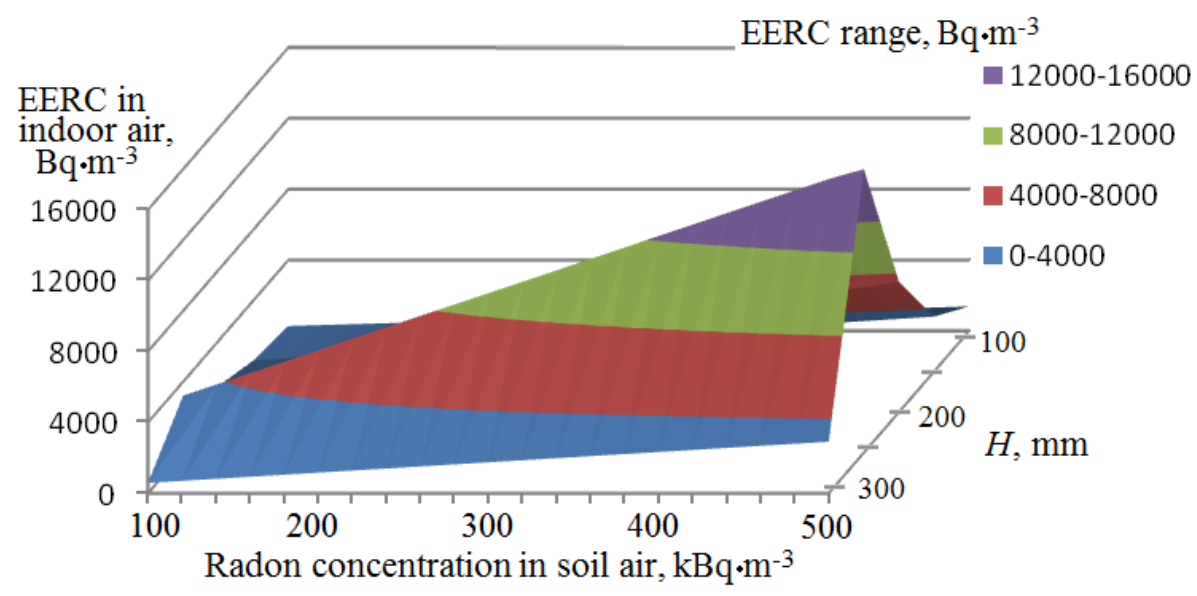

Fig. 1. Dependence of radon levels in a room with a single-layer floor construction on the base slab thickness and radon concentration in the soil air

Table 2. The dependence of the radon diffusion coefficient on the concrete slab thickness [13]

\begin{tabular}{|l|c|c|c|c|c|}
\hline Slab thickness $H, \mathrm{~mm}$ & 100 & 150 & 200 & 250 & 300 \\
\hline Radon diffusion coefficient $D \cdot 10^{-8}, \mathrm{~m}^{2} \cdot \mathrm{s}^{-1}$ & 11 & 7.5 & 5.3 & 3.7 & 2.9 \\
\hline
\end{tabular}

We can see at the Fig. 1 that the radon concentrations in the indoor air of the buildings with a single-layer floor construction significantly exceeds the established levels and can reach tens of thousands of $\mathrm{Bq} \cdot \mathrm{m}^{-3}$. Consequently, one base slab is not able to effectively limit the radon entry from the soil into the building and it is necessary to include in the floor construction additional layers with high resistance to radon penetration. We estimate the radon resistance of the floor construction required to ensure the radon safety of the building, expressing it from equations (6) and (7)

$$
R=A \cdot S \cdot F /(E E R C \cdot V \cdot \lambda)
$$

For equivalent equilibrium radon concentration, a range of it values from 40 to $80 \mathrm{~Bq} \cdot \mathrm{m}^{-}$ ${ }^{3}$ can be considered acceptable for territories of any radon hazard degree (Fig. 2). 


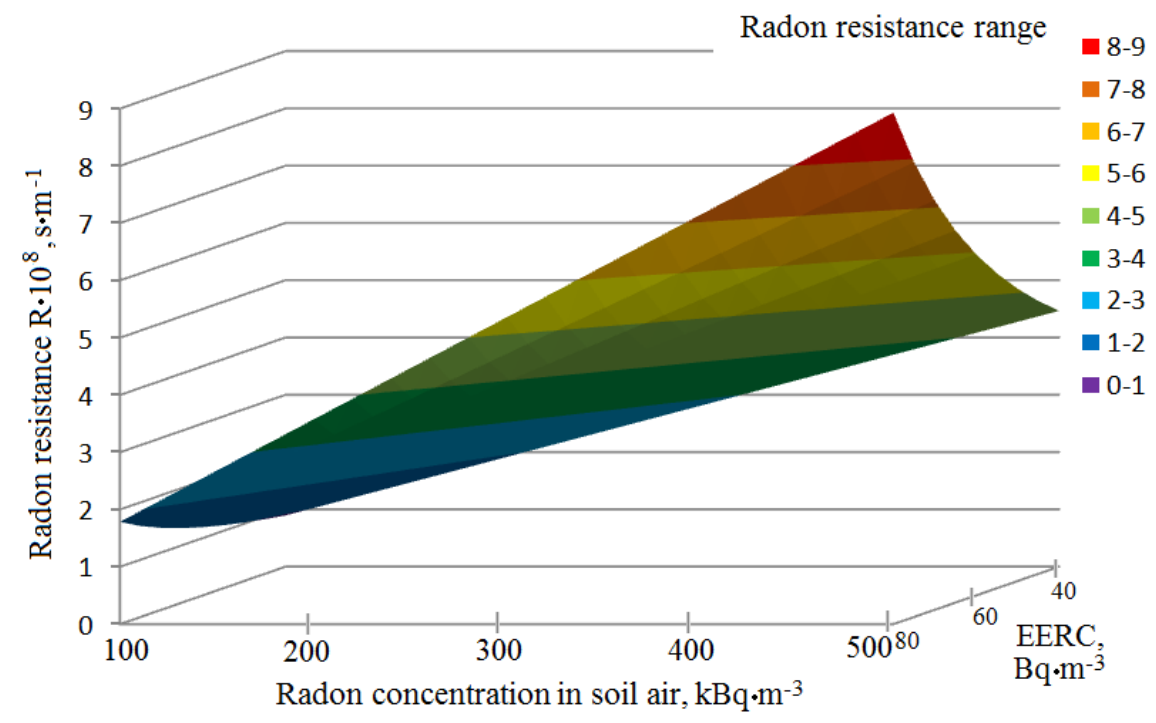

Fig. 2. Evaluation of the required radon resistance of the floor construction

From the Fig. 2 it can be seen that the total radon resistance of the floor structure, which is necessary to ensure the radon safety of the building on uranium-rich soils, lies in the range from $10^{8}$ to $9 \cdot 10^{8} \mathrm{~s} \cdot \mathrm{m}^{-1}$. Such hydro-gas-insulating properties of rolled-polymerpolymer materials, polymer concrete and membranes based on polyethylene and polyolefin have similar radon-protective characteristics $[8 ; 13]$. The use of any of these materials in radon-hazardous areas in combination with the base plate in the floor construction will ensure a safe radon environment in the building.

\section{Conclusion}

The results obtained in this study allow us to conclude that even in radon-hazardous areas, radon safety of buildings can be ensured only by passive protection technologies. However, the following conditions must be met:

1) Air tightness of the building underground shell must be ensured in order to avoid convective radon inflow from the soil;

2) It is advisable to use two layers with high radon resistance: a reinforced concrete slab and a roll of bitumen-polymer material (membrane) in the floor construction;

3) The typical radon resistance of radon barriers materials (bitumen and polyolefin products) is about $10^{9} \mathrm{~s} \cdot \mathrm{m}^{-1}$, which is several orders of magnitude higher than the similar characteristics of reinforced concrete slabs. Therefore, in a multi-layered foundation the base slab thickness should be determined in terms of providing the required bearing capacity.

\section{References}

1. F. Wang, I.C. Ward, The development of a radon entry model for a house with a cellar, Building and Environment, 35, 615-631 (2000). 
2. A.V. Vasilyev, I.V. Yarmoshenko, M.V. Zhukovsky, Low air exchange rate causes high indoor radon concentration in energy-efficient buildings, Radiation Protection Dosimetry, 164-4, 601-605 (2015).

3. N.V. Bakaeva, A.V. Kalaydo, Analytical model for calculation the radon-protective characteristics of underground walling, IOP Conference Series: Materials Science and Engineering, 456, 012102 (2018). DOI:10.1088/1757-899X/456/1/012102.

4. L.A. Gulabiants, M.I. Livshits, S.V. Medvedev, Determination of radon load on underground walling of a building, Academy, 1, 122-128 (2016).

5. L.A. Gulabiants, Radon hazard. Terms, criteria, signs, ANRI, 1, 12-14 (2013).

6. P.S. Miklyaev, T.B. Petrova, Mechanisms of formation of radon flux from the soil surface and approaches to assessing the radon hazard of residential areas, ANRI, 2, 2-16 (2007).

7. L.I. Khorzova, P.A. Sidyakin, E.G. Yanukyan, Radiation situation at construction sector objects in Caucasus Mineral Waters region and prospects of its decrease, Procedia Engineering 2: Second International Conference on Industrial Engineering, ICIE 2016, 2031-2035 (2016).

8. B.P. Jelle, Development of a model for radon concentration in indoor air, Science of the Total Environment, 416, 343-350 (2012).

9. A.G. Scott, Modeling radon sources and ingress, The 1993 International Radon Conference IV, 66-74 (1993).

10. H. Kojima, K. Nagano, Dependence of barometric pressure, wind velocity and temperature on the variation of radon exhalation, Proceedings of the 2000 International Radon Symposium, NJ III - 6.1-6.11, (2000).

11. K.K. Al-Ahmady, D.E. Hintenlang, Assessment of temperature-driven pressure differences with regard to radon entry and indoor radon concentration, Proceedings of the 1994 International Symposium on Radon and Radon Reduction Technology. Atlantic City, NJ III - 6.1-6.11, (1994).

12. T. Kohl, F. Medici, L. Rybach, Numerical simulation of radon transport from subsurface to buildings, J. of Appl. Geophysics, 31, 145-152 (1994).

13. L.A. Gulabiants, Manual on the design of antiradon protection of residential and public buildings ( NO «FAN-NAUKA», Moscow, 2013). 